\title{
Improving Health, Safety, and Profits in Extended Hours Operations (Shiftwork)
}

\author{
Alex KERIN ${ }^{1 *}$ and Acacia AGUIRRE ${ }^{1}$ \\ ${ }^{1}$ Circadian Technologies, 24 Hartwell Avenue, Lexington, MA 02421, USA \\ Received September 14, 2004 and accepted October 20, 2004
}

\begin{abstract}
Circadian Technologies, Inc. (CIRCADIAN) is an international consulting firm that for over $20 \mathrm{yr}$ has helped employees better cope with shiftwork, while ensuring their employers reduce costs and maximize profits. This paper describes two of the methods employed to reduce accidents, absenteeism, and turnover, while improving morale and productivity in extended hour operations (shiftwork). Shiftworkers rarely receive on-the-job training to help them cope better with the rigors of working nights, evenings, and early mornings. A pre- and post-training study by CIRCADIAN demonstrated improvements in health and fatigue indices, and an increase in daytime sleep length. Companies who provide shiftwork lifestyle training also have lower rates of absenteeism and turnover compared to companies that do not provide training. The second intervention described in this paper is a novel method of shift scheduling. There are thousands of potential schedules, so how does a company choose the best schedule for their facility? The answer lies in allowing employees to be involved in the process of selection. This results in a workforce that experiences less fatigue, turnover and absenteeism, and higher morale.
\end{abstract}

Key words: Shiftwork, Schedule, Training, Health, Fatigue, Turnover, Absenteeism, Circadian rhythms

\section{Introduction}

CIRCADIAN is a spin-off from Harvard Medical School-one of the premier medical research institutes in the United States. The founder of the company, Dr. Martin Moore-Ede, who was working at the University, was approached by a mining company whose shift schedule was so poorly designed that accidents were commonplace occurrences. Realizing the need for this service, Dr. MooreEde formed CIRCADIAN, and twenty years later, CIRCADIAN has worked with hundreds of the largest companies in the U.S. and worldwide, positively affecting the lives of many hundreds of thousands of extended hours employees.

Recently, CIRCADIAN put a price on the cost of extended hours operations in the United States. Five key cost areas were identified that are often not optimized in shiftwork operations: productivity, turnover, absenteeism, accidents and health care costs. Based on data collected by CIRCADIAN $^{1)}$, and information from academic and other sources, the excess cost of non-optimized extended hours operations in the U.S. is approximated at $\$ 206$ billion per year, or approximately $\$ 8,600$ per shiftworker per year (based on 24 million shiftworkers). Clearly there is a business case to improve and optimize shiftwork operations in the U.S. and worldwide. CIRCADIAN's most popular products include helping managers determine their opportunity to assist their company reduce its costs, risk and liabilities of managing extended hours operations, working with managers and employees to assess staffing levels and implement new work schedules, training for extended hours managers and employees to help them manage and cope better, and health screening.

*To whom correspondence should be addressed. 


\section{Training Employees}

Shiftworkers face considerable challenges compared to their day-working counterparts. Family and social life can suffer ${ }^{2-5)}$ and health can also be affected if not properly managed ${ }^{6,7}$. Shiftwork has been associated with an increased risk of cardiovascular disease ${ }^{8,9)}$ gastrointestinal disorders ${ }^{10)}$, obesity $^{7)}$, diabetes ${ }^{11)}$ and obstructive sleep apnea ${ }^{12)}$. Sleep quality and quantity is often lower for those working at night, or starting early in the morning ${ }^{13,14}$. The increased prevalence of health problems often results in an increased use of medication $^{15)}$.

These issues clearly affect the employee, but the employer can also incur extra costs as a result of increased absenteeism, turnover, medical care, safety incidents and production errors. While all of these challenges can be effectively managed, the techniques that an employee can use to help mitigate shiftwork problems are not obvious, and unlike other skills, cannot be "picked up on the job". Unfortunately, as illustrated in Table 1, a recent survey found that the vast majority of shiftwork facilities in the U.S. reported that they offer no form of shift work lifestyle training for their shiftworkers ${ }^{1)}$. Equally, only one in 20 facilities involve the families of the shiftworker in any training that they do provide. Involving families can be a very effective tool, as it provides them with an understanding of the employee's need for sleep, proper nutrition, and how best to organize household chores and family activities around a shiftworker's schedule. Indeed, shiftwork affects the entire family, not just the shiftworker. Involving the family not only helps to provide support and re-enforcement in the home, but also maximizes the training's long-term value.

\section{Employee Benefits}

The impact and value of lifestyle education and training for extended hours employees has long been a subject for discussion ${ }^{16}$. Recently, a joint study by CIRCADIAN and a major surface mining company found a positive impact on a group of heavy equipment operators who were provided training on "Managing A Shiftwork Lifestyle" at one of the mine sites. This impact was not just limited to areas of sleep, but also demonstrated improvement in overall health indicators.

The "Managing a Shiftwork Lifestyle" program was designed to assist extended hours employees in coping with the special issues associated with working long, irregular, or night and evening shifts. A training session consists of small groups of employees (between 10 and 50) and is
Table 1. Shiftwork lifestyle training

\begin{tabular}{lc}
\hline Type of Shiftwork Lifestyle Training & \% of Facilities (2003) \\
\hline No training & $77.7 \%$ \\
Training for shiftworkers & $17.6 \%$ \\
Training for shiftworkers and their families & $4.7 \%$ \\
\hline
\end{tabular}

conducted by an expert trainer, and in this instance included participation of spouses or partners. The training is conducted in a single session, lasting about four hours. The content includes practical information on health and safety including special considerations for a safe and healthy shiftworker diet, managing fatigue and alertness levels, how to get better sleep, tips for using naps effectively, and balancing work and home life. The sessions are participatory so that individuals are able to identify particular problem areas, and share tips with each other.

The sessions tend to have the most impact when spouses or partners are invited, as shift work affects the whole family. Equally, the sessions are most successful when they are conducted during company time, rather than being voluntary outside of work time. The training can be less effective when the popular opinion is that the current shift schedules are not working well, or there are other employee, management, or labor organization issues. In this case, employees may feel that the training is being thrust upon them without fixing other causes of dissatisfaction.

\section{Methods}

The study began with the collection of sleep/wake/activity data from operators at the mine, who volunteered to fill out sleep/wake logs for a 28 -d shift cycle. These operators, plus an additional three who did not collect sleep/wake/ activity data, completed a diagnostic survey about their sleep habits, lifestyle, family/home life, fatigue, alertness, health and safety to establish a pre-implementation baseline. After this initial data collection, the operators and their spouses/ partners then attended the "Managing A Shiftwork Lifestyle" training workshop. The course was not designed to be prescriptive, but rather to provide factual information on the solutions to the special challenges of shiftwork. Approximately six weeks following the training session, $74 \%$ of the original operators filled out an additional month of sleep/wake logs and $68 \%$ of the original group completed a post-implementation survey. The pre- and postimplementation data were then compared to determine the net impact of the training. 


\section{Discussion of Key Employee Findings}

Although there was no schedule change associated with the training, there were some significant differences between the pre- and post-implementation data with regard to the employees' perception of the schedule. For example, before the training, $41 \%$ found it "very" or "often" difficult to fulfill domestic responsibilities; after the training, only $23 \%$ felt that way. This can often be attributed to a generally better overall management of work and family balance following the training. Similarly, $46 \%$ reported difficulty finding adequate time for entertainment and recreational activities prior to the training, compared to only $23 \%$ after the training. It is also striking that in the post-implementation survey, $77 \%$ felt that their overall health would improve with a different schedule, as compared to $59 \%$ in the preimplementation survey. This could be the result of better understanding of how their own personal circadian rhythms are impacted by their current schedule, coupled with the knowledge of how different schedule configurations might be easier for them to work.

Included in the survey were a series of scientifically validated instruments to evaluate health status, such as sleepiness index, gastrointestinal index, and sleep disorder questionnaire. The post-implementation improvement in the gastrointestinal index was quite dramatic, dropping from a score of 17.9 to 13.6 , versus a U.S. shiftwork norm of 12. $7^{16)}$. Heartburn, indigestion and other forms of gastrointestinal problems are frequent complaints for shiftworkers, so the significant downward trend from preto post-implementation results for this company was favorable. This correlates well with other results from the survey that indicate a high percentage of operators were more aware of good nutrition and were incorporating healthy eating habits into their lifestyle. The reduction in gastrointestinal score potentially represents a significant reduction in medical costs for the company, since a recent study by CIRCADIAN found that employees reporting frequent gastrointestinal problems also report a higher use of medication to treat these problems ${ }^{18)}$.

Excessive use of caffeine, which is generally defined as drinking more than four $12 \mathrm{oz}$. servings in a 24 -h period, decreased from $24 \%$ of employees to $16 \%$ during off-duty hours. Even more impressive was the decrease in excessive consumption during the night shifts, from $32 \%$ to only $8 \%$ of participants drinking 4 or more cups of coffee. This reduction in caffeine use can result in significant improvements in employee health, since CIRCADIAN data showed that a high caffeine use is related with an increased frequency of both gastrointestinal disorders and sleep disorders $^{18)}$.

One of the more notable results from the sleep/wake/ activity logs was a significant increase in average daily sleep length when working nights. The amount of sleep obtained during the daylight hours (when working night shifts) increased a full hour to $5.8 \mathrm{~h}$, as compared to the $4.8 \mathrm{~h}$ obtained prior to the training (a $21 \%$ increase). This additional daytime sleep when working night shifts is attributed to a better understanding of sleep and sleep management techniques.

This is further reflected by the fact that $67 \%$ of those surveyed reported getting more than $5 \mathrm{~h}$ of daytime sleep when working night shifts, compared to only $45 \%$ prior to the training. This again illustrated a better understanding of sleep and commitment to improve one's sleep quantity and quality. This is also confirmed by the fact that prior to training, $82 \%$ had stayed awake for more than $18 \mathrm{~h}$ at some point in the previous week, while after the training only $67 \%$ had done so. More than half (54\%) indicated making changes in their sleeping environment to further enhance their ability to get to sleep and stay asleep, especially during the daylight hours when they were working the night shifts.

Improved sleep and reduced fatigue directly correlates with improved alertness, safety and performance.

\section{Employee Conclusions and Recommendations}

The positive impact of the training was readily apparent in the post-implementation data analysis. Both the employee survey and the sleep/wake/work log analysis confirmed marked improvements resulting from the shiftwork lifestyle training. These results underscore the need to provide training and education for extended hours employees on how to better manage the special issues and challenges they face.

Although training alone is not sufficient for a comprehensive fatigue management program, the results of this study indicate that it can serve as a core element for a strong plan. In the final analysis, the program was very well received by both managers and operators. Employee feedback was that they felt better and were more alert. Operations Managers stated that, "Overall, the program was a very positive breakthrough".

\section{Employer Benefits}

Given the results of this training study, it would also be expected that employer costs would decrease as a result of employee lifestyle training. While data is not yet available 


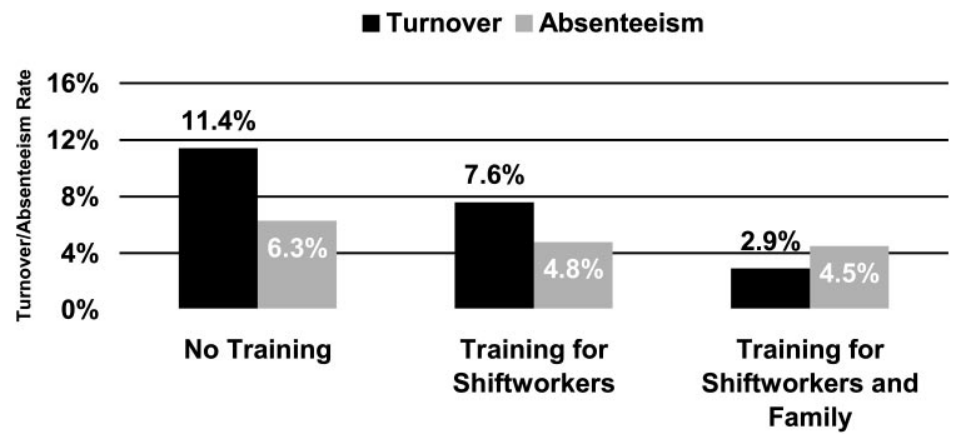

Fig. 1. Variation in absenteeism and turnover by shiftwork lifestyle training offered at facility.

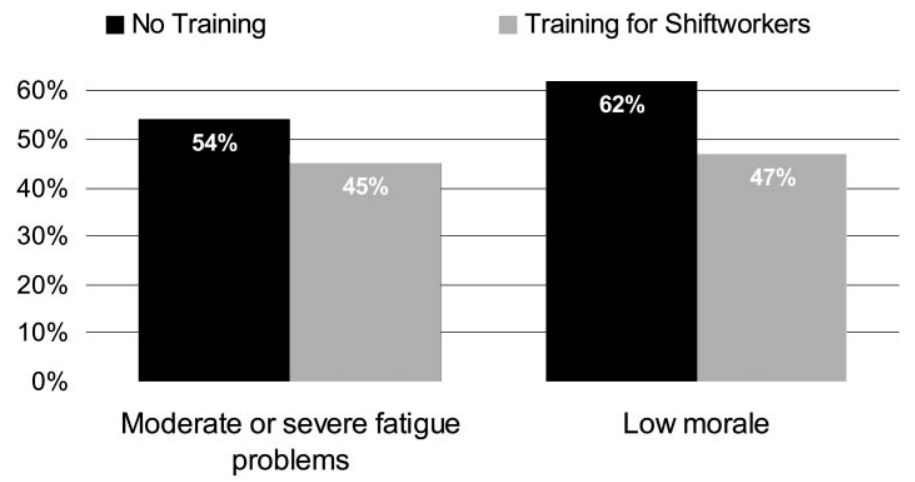

Fig. 2. Shiftwork lifestyle training and the percent of facilities reporting fatigue and morale issues.

from the test site, results from CIRCADIAN's Shiftwork Practices 2004 indicate that this is the case ${ }^{1)}$. This survey of 550 managers of extended hours operations addressed questions concerning absenteeism, turnover and the level of shiftwork training provided to employees.

Facilities that provided training to shiftworkers also exhibited lower levels of turnover and absenteeism, as illustrated in Fig. 1. These companies had significantly lower costs as a result of the lower turnover (7.6\% vs. $11.4 \%$ ) which amounts to annual cost savings of $\$ 952$ per worker. These facilities also had reduced absenteeism $(4.8 \%$ vs. $6.3 \%)$, saving an additional $\$ 940$ per shiftworker per year. Thus, total savings of $\$ 1,892$ per employee per year were suggested by this extensive survey. Absenteeism costs are calculated from the additional pay that a replacement worker receives when an employee is absent (presumed to be at an overtime rate). Turnover costs are calculated from the average cost of recruiting, hiring, and training a new employee, as reported by managers of extended hours operations.

Other results from the Shiftwork Practices 2004 survey show that $54 \%$ of facilities that provide no training have severe or moderate fatigue issues, compared to $45 \%$ of those with training, as illustrated in Fig. 2. Morale also suffers: $38 \%$ of facilities with no training have good or excellent morale, compared to $53 \%$ of facilities with shiftworker training, and $82 \%$ of facilities with training for shiftworkers and their families. Clearly, other savings may also be possible, such as decreased health care costs, safety incident costs and workers' compensation costs, and increased productivity. The cost of the training ranges between $\$ 50$ and $\$ 150$ per employee, depending on the number of employees in each training session. Given the savings in absenteeism, turnover, and other key performance areas, it is clear that the training is extremely cost-effective. As employees are provided with a comprehensive information folder on the training content, the training is potentially effective for many years.

\section{Training Conclusions}

The results of both employer and employee analyses clearly indicate that shiftworker lifestyle training provides 
measurable benefits for the company, its employees, and their families. In addition to improved alertness levels, health, and quality of life, such training can also reduce accidents, decrease legal liability, and reduce overall operating costs.

\section{Employee Involvement in Shift Scheduling Significantly Improves Facility Performance}

There are literally thousands of different work schedules in use, but contrary to popular belief, there is no "golden schedule" that surpasses all others ${ }^{19,20)}$. The optimal work schedule for any facility is a balance between operational requirements, employee preferences and lifestyle issues and the human factors considerations that influence safety and employee performance ${ }^{21-25)}$.

This part of the paper demonstrates that extensive employee participation in the schedule selection and change process is critical to the initiative's success. Employee involvement in schedule redesign, through education, participatory design, and group implementation, considerably increases both financial and performance benefits, compared to schedules changed by management mandate alone ${ }^{25-30}$.

\section{The Pros and Cons of Scheduling Processes}

Surveys of facility managers demonstrate that work schedules developed through employee-driven processes (vs. management mandated) can lead to lower levels of absenteeism and turnover, as shown in Fig. $3^{1)}$. A reduction in absenteeism and turnover by the levels reported in the survey results in average direct cost savings of $\$ 1,880$ per extended hours employee. Again, absenteeism costs are calculated from the additional pay that a replacement worker receives when an employee is absent (presumed to be at an overtime rate). Turnover costs are calculated from the average cost of recruiting, hiring, and training a new employee, as reported by managers of extended hours operations. Fatigue is also lower in facilities where employees chose the schedule $-6.5 \%$ of managers in these facilities reported severe fatigue problems, compared to $13 \%$ of managers who mandated schedules.

Work schedules should be regularly re-evaluated in order to maximize the productivity and safety of the workers and minimize the operational costs of the facility. The CIRCADIAN Shiftwork Practices Survey 2004 demonstrates that $8 \%$ of $24 / 7$ facilities have used their current schedule for less than $1 \mathrm{yr}, 23 \%$ have used their current schedule for 2 to $5 \mathrm{yr}, 25 \%$ have used their current schedule for 5-10 yr, while $44 \%$ haven't changed schedules in over $10 \mathrm{yr}$. Some facilities

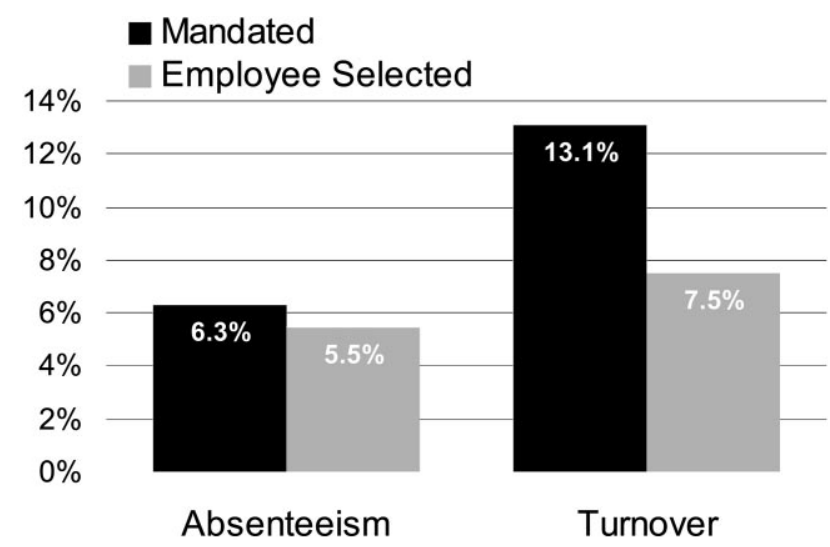

Fig. 3. Absenteeism and turnover rates in facilities that mandate shift schedules vs. those that allow employees to select schedules.

surveyed revise their schedules every $2-3$ yr to adjust to changing business conditions. Others keep the same schedule for $10 \mathrm{yr}$ or more, with a few dating back $50 \mathrm{yr}^{1)}$.

The most frequently reported reasons for redesigning the work schedule in 2001 and 2002 were: ${ }^{1)}$

- to adjust staffing levels or number of crews (e.g. to permit training time, or to start a new department)

- to accommodate business expansion or contraction that requires changes in the work hours or days in a week (e.g. a move from 5-d to 7-d operations, or, as in the current economic environment, from 7-d to 5-d operations)

- to actively recruit and retain the best employees in the area

- to change from a 'crisis' to a 'proactive' mode for staffing and scheduling

- when an operational risk assessment shows that the existing schedule is causing excess employee risks (accidents and lost-time injuries, employee turnover, complaints of excessive fatigue)

- when there are significantly higher levels of absenteeism, overtime, or turnover than would be expected for the industry and geographical area

- changing demographics of the workforce (e.g. more younger employees, more women than previously) make the previous schedule no longer suited to employee lifestyle

- employee complaints had reached all time high levels

\section{Specific Benefits of Employee Involvement}

Employee participation in the process of designing and implementing the new work schedule is just as important as the characteristics of the new work schedule itself ${ }^{19,25,31-33,35,36)}$. 
Studies comparing schedule implementation methods have shown that employee involvement in schedule redesign considerably increases the benefits, compared to schedules changed by management mandate alone ${ }^{25-30)}$, including:

- increased worker satisfaction with schedule design

- decreased unscheduled absences from illness

- maintained teamwork among employees as well as inrole and extra-role performance on individual levels

- decreased physical and psychological circadian malaise and overall tiredness associated with shiftwork

- improved daytime sleep quality

- improved quality of employees' home and social lives

- decreased turnover and number of vacant positions

- increased organizational commitment

- improved employee understanding of administrative issues involved in management of the facility

- reduced employee complaints

Employee involvement in the scheduling selection process can be critical to preempting unrest and creating strong employee-level support. In unionized facilities, research suggests that the cooperation of trade union members is critical to the success and final support of the chosen schedule $^{24}$. Each employee affected by the schedule should be equally involved in its design. Although each employee will bring his or her own preferences into the process, individual preferences are stable for periods of 6 months and can be grouped using cluster analysis to extract the significant preferences from the facility as a whole ${ }^{34}$.

The design of a new schedule should be adapted to the conditions of the particular workplace or operation, and should take into account the local operational needs and specific characteristics of the workforce. As discussed, this can be accomplished by involving both employees and local management in the process. Educating and training of managers and employees about the challenges of shiftwork and how to cope with them, and understanding the basic ergonomic criteria of schedule design will contribute to a better schedule. Finally, the participation of an independent, expert third party has proved to increase the success of the process. The expert third party not only would provide expert advice on ergonomic scheduling criteria, but would have a major role facilitating the process, helping labor and management combine conflicting interests and reaching compromises. CIRCADIAN's process of helping managers and employees choose the right schedule consists of:

- planning meetings with management to determine what schedules are possible (e.g. what time periods need to be covered, staffing levels, etc.)

- the forming of a task team of management, union member, and employees that will help facilitate the process

- a series of training sessions that educate employees on the pros and cons of different schedules

- a survey to determine which schedule types are most appropriate for the workforce

- a voting on the schedule patterns provided by CIRCADIAN to most likely fulfill the wishes of the workforce

- resolving of pay issues/vacation, and implementation of the new schedule

As indicated above, workplaces that use schedules that were chosen by the employees enjoy lower turnover and absenteeism compared to workplaces where schedules are chose by management. If only 50 percent of the cost difference associated with the excess turnover and absenteeism $(\$ 1,880 \times 50 \%=\$ 940)$ was realized per employee in the first year alone, a plant with 100 employees would save almost $\$ 100,000$. This compounded with the fact that this schedule would not likely have to be reassessed for at least $5 \mathrm{yr}$ results in a considerable return on investment.

\section{Shift Scheduling Conclusions}

The success of the work schedule in meeting the goals, maximized productivity and safety of the workers and minimized operational costs and risks of the facility, will depend solely on who choose the work schedule, and how they choose it. Facilities, in which employees are consulted during the scheduling process, experience fewer accidents, improved morale, decreased absenteeism and turnover, and optimized production levels. Employee-driven scheduling processes, in which operational requirements, employee preferences, and physiological factors are optimized, represent the best approach to designing and implementing new shift schedules.

\section{Overall Conclusions}

The two examples demonstrate how CIRCADIAN improves the lives of employees, and decreases costs for employers. These two products (training and scheduling) are two of the many fatigue management and cost reduction programs that CIRCADIAN provides. 


\section{References}

1) CIRCADIAN's Shiftwork Practices 2004 survey (2004) A survey of 600 employers of shift workers.

2) Newey CA, Hood BM (2004) Determinants of shiftwork adjustment for nursing staff: the critical experience of partners. J Prof Nurs 20, 187-95.

3) van Amelsvoort LG, Jansen NW, Swaen GM, van den Brandt PA, Kant I (2004) Direction of shift rotation among three-shift workers in relation to psychological health and work-family conflict. Scand J Work Environ Health 30, 149-56.

4) Monk TH (1994) Shiftwork. In: Principles and Practice of Sleep Medicine, $2^{\text {nd }}$ ed. eds. by MH Kryger,T Roth, WC Dement, WB Saunders, Philadelphia.

5) Presser $H$ (2000) Nonstandard work schedules and marital instability. J Marriage Family 62, 93-100.

6) Costa G (1997) The problem: shiftwork. Chronobiol Int 14, 89-98.

7) Knutsson A (2003) Health disorders of shift workers. Occup Med 53, 103-8.

8) Tenkanen L, Sjoblom T, Harma M (1998) Joint effect of shiftwork and adverse life-style factors on the risk of coronary heart disease. Scand J Work Environ Health 24, 351-7.

9) Boggild H (2000) Shiftwork and heart disease. Epidemiological and risk factor aspects. Ph.D. thesis. University of Aarhus, USA.

10) Costa G, Apostoli P, D’Andrea F, Gaffuri E (1981) Gastrointestinal and neurotic disorders in textile shift workers. In: Night and Shift Work: Biological and Social Aspects. eds. by Reinberg A, Vieux N, Andlauer P, Pergamon Press, Oxford, 187-96.

11) Nagaya $T$, Yoshida $H$, Takahashi H, Kawai M (2002) Markers of insulin resistance in day and shiftworkers aged 30-59 years. Int Arch Occup Environ Health 75, $562-8$.

12) Stoohs RA, Bingham LA, Itoi A, Guilleminault $C$, Dement WC (1995) Sleep and sleep-disordered breathing in commercial long-haul truck drivers. Chest 107, 1275-82.

13) Kecklund G, Åkerstedt $T$ (1995) Effects of timing of shifts on sleepiness and sleep duration. J Sleep Res 4 (Suppl. 2), 47-50.

14) Aguirre A, Cerezo V, Rodriguez-Valdes JL, Lopez-Aira JM (1990) Sleep and subjective fatigue in Spanish railway workers as a function of working schedules. In: Shiftwork: health, sleep and performance. eds. by Costa G, Cesana G, Kogi K, Wedderburn A, Peter Lang,
Frankfurt.

15) Aguirre A, Foret J (1994) Irregularity of working hours in railway workers and types of complaints. Int Arch Occup Environ Health 65, 367-71.

16) Tepas DI (1993) Educational programmes for shiftworkers, their families, and prospective shiftworkers. Ergonomics 36, 199-209.

17) Data from CIRCADIAN's database of 18,500 shift workers in the US (1997-2004).

18) Aguirre A (2003) Health in extended hours operations: understanding the challenges, implementing the solutions. CIRCADIAN, Lexington.

19) Knauth P (1993) The design of shift systems. Ergonomics 36, 15-28.

20) Gartner J, Wahl S (1998) The significance of rota representation in the design of rotas. Scand J Work Environ Health 24 (Suppl 3), 96-102.

21) Gissel A, Knauth P (1998) Knowledge-based support for the participatory design and implementation of shift systems. Scand J Work Environ Health 24 (Suppl 3), 88-95.

22) Jeppesen HJ, Boggild H (1998) Management of health and safety in the organization of worktime at the local level. Scand J Work Environ Health 24 (Suppl 3), 817.

23) Kogi K (1997) Implications of flexible work systems for work studies. J Hum Ergol 26, 89-97.

24) Sakai K, Watanabe A, Kogi K (1993) Educational and intervention strategies for improving a shift system: an experience in a disabled persons' facility. Ergonomics 36, 219-25.

25) Smith PA, Wright BM, Mackey RW, Milsop HW, Yates SC (1998) Change from slowly rotating 8-hour shifts to rapidly rotating 8 -hour and 12 -hour shifts using participative shift roster design. Scand J Work Environ Health 24 (Suppl 3), 55-61.

26) Ala-Mursula L, Vahtera J, Kivimaki M, Kevin MV, Pentti J (2002) Employee control over working times: associations with subjective health and sickness absences. J Epidemiol Community Health 56, 272-8. Comment in: J Epidemiol Community Health 56, 244 5.

27) Beltzhoover M (1994) Self-scheduling: an innovative approach. Nurs Manage 25, 81-2.

28) Bradley DJ, Martin JB (1991) Continuous personnel scheduling algorithms: a literature review. J Soc Health Syst 2, 8-23

29) Holtom BC, Lee TW, Tidd ST (2002) The relationship between work status congruence and work-related 
attitudes and behaviors. J Appl Psychol 87, 903-15.

30) Teahan B (1998) Implementation of a self-scheduling system: a solution to more than just schedules! J Nurs Manage 6, 361-8. Erratum in: J Nurs Manag 7, 65.

31) Hauburger NM (1997) Implementation of selfscheduling in the poison center. Vet Hum Toxicol 39, 175-7.

32) Knauth $P$ (1997) Changing schedules: shiftwork. Chronobiol Int 14, 159-71.

33) Kogi K, Di Martino V (1995) Trends in participatory process of changing shiftwork arrangements. Work Stress 9, 298-304.

34) Gray JJ, McIntire D, Doller HJ (1993) Preferences for specific work schedules: foundation for an expertsystem scheduling program. Comput Nurs 11, 115-21.

35) Conrad-Beschart H (1990) Designing new shift schedules: participation as a critical factor for improvement. In: Shiftwork: Health, Sleep and Performance. eds. by Costa G, Cesana G, Kogi K, Wedderburn A, 277-82, Peter Lang, Frankfurt.

36) Jeppesen HJ, Boggild H (2000) Redesigning shift schedules though a participatory intervention approach. In: Shiftwork in the 21st century. eds. by Hornberger S, Knauth P, Costa G, Folkard S, 363-8, Peter Lang, Frankfurt. 